\title{
GPS Based City Wise Integration System for City Vendors
}

\author{
${ }^{1}$ Vaidehi Shrivastava, ${ }^{2}$ Harsh Dhakad, ${ }^{3}$ Samarth Bajaj ${ }^{*}{ }^{4}$ Viplove Divyasheesh
}

Dept. of Computer Science \& Engineering Indore Institute of Science and Technology, Indore MP, India

\begin{abstract}
:
This research paper focuses on creating a platform for street vendors which will improve their availability to users by displaying their real-time location nearby user's locality along with their respective services. This doesn't require any expensive hardware allowing users to get notified when a hawker providing services of user interest passes through her street.

Small-scaled business people like hawkers have a large impact on a country's economy because of their large population in developing countries like India. Due to minimal exposure to technology, they use classic business methods which struggle to uphold their position against tough competition from large organizations. These hawkers can be uplifted by providing a platform which will be based on advanced business strategies developed on the basis of those which are introduced by modern economists and business ideologists.

This platform will be as useful for static vendors as it is for dynamic vendors not limiting to a single service but to all street vendors present despite the service they provide. Hence, users won't have to look for vendors floating in the streets as their location will be visible on the map in the application.
\end{abstract}

Keywords: Real-time Location, Advanced Business Strategies, GPS

\section{Introduction}

Currently, there isn't any existence of a platform for street vendors by which a user who wants to buy something from street vendors can easily get their location. In this paper, we will understand how we can make it possible.

This paper includes simple steps in which the above discussed platform can be easily implemented. First, we need street vendors to get them registered on our platform. At the time of registration, basic details such as name, gender, contact number, profession, etc. will be asked. The vendor will then get registered on the platform. If a user wants to search for a particular street vendor, he can search him/her through his/her profession. The platform will then provide the required results based on profession and the availability of nearest vendors for that particular location.

The platform will be displaying real time map of the location/city which will include the dynamic
Location of street vendors. To avail it's services, user has to provide access to the platform to set an alert which rings when the requested type of vendor enters the user's range.

The main purpose of this research paper is to find out hawker's real time location which can be achieved through 3 ways:

- Global Positioning System: It is a satellitebased navigation system which allows ground users to determine their exact location. It gives good accuracy and doesn't require a smartphone.

- Internet: It is the best way to find out Hawker's location. It gives high accuracy but it requires a smart phone.

- Contact Number: We can get the location of hawkers using their mobile number with the help of Cell Tower. 


\section{Literature Review}

Of all the professions which are known at present, street vending is the least appreciated among all of them. Possible reasons at lower level could be that street vending isn't a professional way in the emerging globalisation. At higher level, one possible drawback could be the unavailability of a platform where all of the street entrepreneurs are integrated together and merged up as a single unit.

But if we dwell deeply into the topic, the above discussed points are purely theoretic in discussion. In India, informal enterprises contribute to around 46\% of GDP outside agriculture, estimated in the study published in a paper by Martha A Chen and Victoria A Beard[1]. The paper published by global research organisation suggests that supporting informal workers is actually an effective way to make developing countries like India, more productive and sustainable.

Now, just have a closer look at some statistics of informal economy constituted by millions in India :

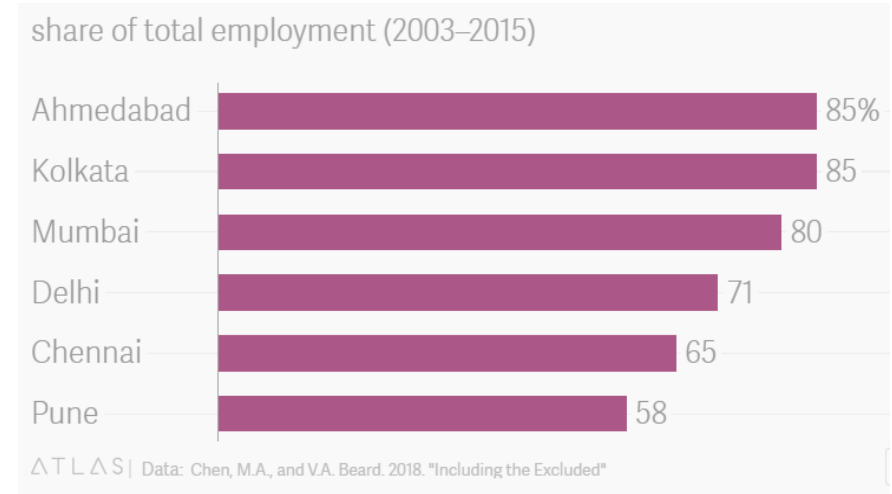

The above information is collected from a working paper published by Martha A Chen and Victoria A Beard which is titled as "Including the Excluded: Supporting Informal Workers for More Equal and Productive Cities in the Global South". This is the fourth paper in WRI's flagship World Resources Report, Towards a More Equal City.

The paper strongly highlights how street vendors contribute to the economic and financial growth of the country. Among all of the mentioned cities, Ahmedabad stood second in the world which constitutes of $85 \%$ of the informal economy in the city which is a very large amount.

Another historic achievement was made by Mr. Arvind Singh, coordinator of National Association of street vendors of India (NASVI). He raised the visibility of vendors by speaking at TEDx BIMTECH[2] about the concentration and contribution of street vendors in India. $\mathrm{He}$ emphasized on three major reasons why vendors are moving from their static zone to street vending. It is because street vending requires less skill, low investment and no economic background to earn livelihood.

In 2004, Mr. Arvind got a big success in gaining national policies for street vendors under which they can enjoy a legal ground for selling goods. He also started hawkers corners in Madhya Pradesh. He had also organised street food festival in many cities which helped vendors to stabilize and promote their activities at higher level. His contribution towards the development in the field of informal economy for the country is appreciable.

\section{Vendors' contribution in country's GDP}

Contribution of vendors in Selected Cities

\begin{tabular}{|l|l|l|}
\hline City & Estimated Employment Generation & $\begin{array}{l}\text { Annual Turnover (in Rs } \\
\text { crore) }\end{array}$ \\
\hline Ahmedabad & 127,000 & 1,007 \\
\hline Patna & 60,000 & 421 \\
\hline Delhi & 200,000 & 1,590 \\
\hline Mumbai & 200,000 & 1,590 \\
\hline Calcutta & 191,000 & 1,518 \\
\hline
\end{tabular}

\begin{abstract}
NSS Estimates
The 50th round of NSSO (1993-94) estimates the number of street vendors as proportion of population as follows:

Urban Area: street vendors constitute $0.89 \%$ of population

Rural Area: street vendors constitute $0.27 \%$ of population.

Total number of street vendors(1991) $=3.6$ million.
\end{abstract}

The above snip is being taken from the official site of NASVI[3]. The estimates are calculated from survey of street vendors report by NASVI, a report which was published on June 2012. It included the condition of street vending in 10 cities in India. The report briefly described globalisation as a major problem restricting the flow of street vendors in the city [4].

\section{Evolution of GPS:}

The concept of GPS started in early 1970s to establish a medium through which military operations can be tracked and to locate distinct positions on the globe. At that time, GPS was not available to civilians and wasn't granted access for 
normal positioning. Actual use of GPS was made alive in 1995 which was specifically designed to track human moments on the ground. At present, there are at least 24 satellites orbiting the earth at an altitude of about 11,000 nautical miles[5].

The global positioning system doesn't require the internet to work with devices. There is a fully standalone GPS receiver embedded in cellular phones which works as a normal GPS. This means that GPS positioning should work even if there is no cellular network. This property of GPS makes it reliable to use for positioning at very general level.

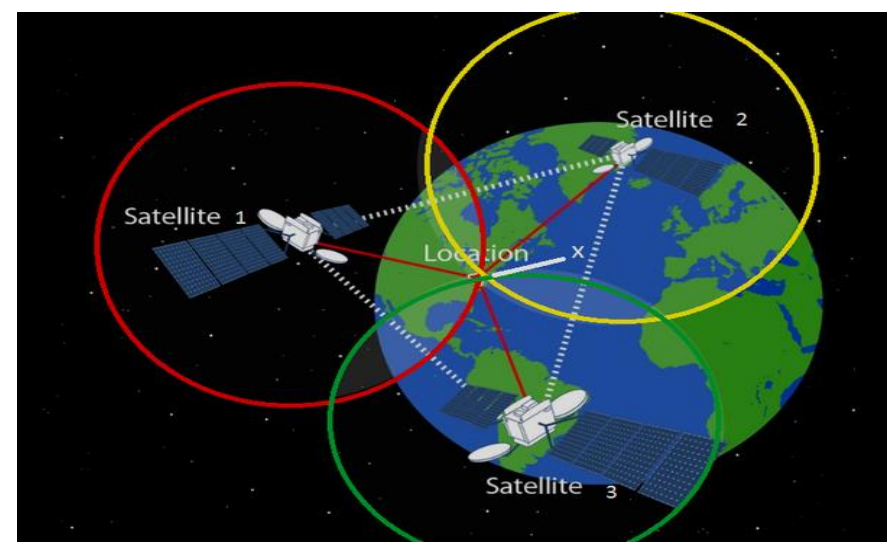

Image source:

https://www.nationalgeographic.org/photo/triangula tion-sized/

GPS doesn't take input from our device. Instead, it gets information from at least four of the 28 satellites in orbit that are devoted for geolocation use.

\section{How does Mobile GPS Work?}

The Mobile's GPS recipient utilizes the information from these circles to triangulate where you are and what time it is. Notice the word triangulation and the specify over that four satellites are required for GPS to work. The fourth signal is utilized to determine altitude so we can get our geolocation information on a map with just three signals.

GPS receivers utilize a considerable amount of power and require an unobstructed perspective of different satellites to work. Obstructions can incorporate tall structures and that implies the places where the most of us live can (and does) experience difficulty getting the information it needs constantly.

\section{The Platform}

\section{Mobile Application}

Smartphones are becoming essentials in day-to-day life and it's all because of their mobility even after containing a fully equipped computer making it a suitable device for this application. So, this will be an ideal choice which will work as a platform. All the various services to be provided will be integrated on this single application which can be made cross-platform hence can be installed on any operating system, be it Android, iOS or any other.

Hawkers might not have a smart-phone so they will have to register on the platform by sending an SMS to a certain number providing the details of their business and they will be able to be tracked live on the application.

The application will help users to locate the registered hawkers in their locality on map. They can also filter the map to locate the hawkers providing certain type of services which users are interested in. An additional feature can be provided for users to be notified when a hawker of user's interest passes from their street. This will help user not to have an eye on the street waiting for the street vendor to arrive.

\section{Maps Integration}

The platform will require a map on which hawker's location will be displayed for user to spot. Here, dynamic map will be used as this require real time location tracking of hawker. So, the developer either needs to create a complete working dynamic map system solely made for this platform which will require large amount of resources at first and free for the rest of time or use the maps provided by various private organisations like Google Maps, OpenLayers, etc which will charge on requests basis.

\section{- Google Maps API}

This is a very popular maps API developed by Google Inc. which provides both static and dynamic maps at low prices based on the monthly loading requests. This provides free dynamic maps usage up to 28000 requests and then $7 \$$ per thousand loading requests. This API is well equipped with decent dynamic features. Also, developer can apply modifications based on the needs of the platform. 
Pros: Accuracy, faster adaptability to changes, powerful dynamic maps.

Cons: Expensive

\section{- TomTom}

A very good alternative to Google Maps if Google Maps sounds a little expensive with great features, though not actually comparable to Google Maps in accuracy and security. This API asks for $0.42 \$$ per thousand loads which is way too much cheaper than the Google Maps API, also it works for both Android and iOS systems.

Pros: Economical

Cons: Less Features, slower adaptability to changes.

\section{- OpenLayers}

For individual developers, if economics is the cause then OpenLayers turns out to be the best option. This is an open-source maps API which provides free use of its map services. Currently, its working on stable 2.x version but soon will be upgraded to 3. $\mathrm{x}$ which will contain better dynamic features.

Pros: Free, Good static maps

Cons: Not updated as compared to competition.

\section{Real-Time Location Tracking}

Being the prime requirement of this application, this is the most necessary need of all. There are various methods to identify the real-time location of a body which are explained below:

\section{- Internet}

This is the most famous and accurate source used worldwide. Almost all the applications currently working in the market uses this medium for the cause. Internet is able to depict the location on very minute levels based on the technology used behind.

Pros: Fast, accurate

Cons: Requires smart phone, high data consumption.

- Cell Tower

This method displays the location on map using the closest cell tower mobile is using.

Pros: Does not consume data, do not need smart phone.

\section{- Global Positioning System}

GPS system uses IMEI number of mobile phones which is unique for each device.

Pros: Accurate, requires phone's IMEI number only.

\section{Cons: None}

\section{Software Economics}

- It is identified that majority of people uses android based smartphones, hence, for starters, it is well suited to develop an android platform. So, the cost of developing an android application should be identified.

- This software requires a $24 * 7$ fully functional location tracking system, so using a cheap map service may lead to crash or false result. Thus, Google Maps API is wellsuited for this platform.

- Hawkers might not have a smartphone but this should not cause problem for them. So, use of GPS system enhances the availability to all hawkers because it doesn't require advanced hardware.

Hence, GPS satellite subscription is required for the developers.

\section{Conclusion}

In this paper, we have compared all the ways by which we can track the real-time location of street vendors. This research paper solves the problem of users as they do not have to wait and check whether the hawker is passing from their location. They will get notified whenever the hawker of their interest is passing from that location. Secondly, the vendors are getting one platform to improve their availability for users. Also, this platform will be useful for all the vendors despite the service they provide.

\section{References}

[1.] Chen, M.A., and V.A. Beard. 2018. "Including the Excluded: Supporting Informal Workers for More Equal and Productive Cities in the Global South." Working Paper. Washington, DC: World Resources Institute. Available online at: www. citiesforall.org 2

Cons: Less accurate 
[2.] Arbind Singh. "Street Vendors - A community of Entrepreneurs". YouTube, uploaded by TEDx Talks, 10 March 2016, www.youtube.com /watch?v=-JlM8Z_fEYY

[3.] National Association of Street Vendors (NASVI). (2014). Statistics and Street Vendors. Retrieved from http://nasvinet.org/newsite/statistics-thestreet-vendors-2/

[4.] Bhowmik, S. K. 2012. Street Vending in Ten Cities in India. Delhi: National Association of Street Vendors of India.

[5.] Ms. Namami Varshney, Dr. Ambuj Kumar Agarwal. 2015. Global Positioning System. 4th International Conference on System Modelling \& Advancement in Research Trends (SMART). College of Computing Sciences and Information Technology (CCSIT), Teerthanker Mahaveer University, Moradabad.

[6.] Google Maps API

https://cloud.google.com/maps-

platform/pricing

[7.] Bhowmik, S. 2001. Hawkers in the Urban Informal Sector: A Study of Street Vendors in Seven Cities. Patna, India: National Alliance of Street Vendors of India

[8.] Alcântara, A., F. Comaru, G. Sampaio, L. Itikawa, L. Kohara, and M.C. Ferro. 2014. Street Vendors and the Right to the City. São Paulo, Brazil: Centro Gaspar Garcia de Direitos Humanos

[9.] OperLayers API - https://openlayers.org/

[10.] TomTom API https://developer.tomtom.com/tomtommaps-apis-developers 